\title{
Moderating Effects of Gender in the Acceptance of Mobile SNS Based on UTAUT Model
}

\author{
Yong Guo \\ School of Information Technology, Jiangxi University of Finance and Economics \\ guoyong_hit@126.com
}

\begin{abstract}
With the proliferation of Mobile SNS, understanding users' acceptance behavior has become an important issue for researchers and service providers. Relevant studies have focused on the acceptance of SNS, little research have been conducted to investigate the gender's moderating effects of Mobile SNS. This paper incorporates perceived enjoyment with UTAUT theory as research base model and investigates the difference between male and female users in the acceptance of Mobile SNS. Data collected from 359 respondents in China is analyzed. The analysis result shows that gender moderates the effects of Social Influence on Behavioral Intention and Facilitating Conditions on Use Behavior.
\end{abstract}

Keywords: gender differences; moderating effects; Mobile SNS; acceptance; UTAUT

\section{Introduction}

Traditional Internet users with PCs are limited by fixed client and difficult to employ location-based services, but mobile communication technology can solve these problems. So, with the popularity of smart phones and 3G/4G Mobile Network, in the past few years there has been a significant growth of Mobile Internet users. Statistics points out Mobile Internet users have reached 500 million in China [1]. On the Mobile Internet, using Mobile Social Networking Services (SNS), such as Weixin, Mobile Microblogging, etc, has become one of the most popular activities [2]. Users can enjoy Mobile SNS anytime and anywhere through smart phones.

Because the number of Mobile SNS users is maintaining a high level, this kind of mobile services have attracted widespread attention [3] and understanding the acceptance of Mobile SNS has become a hot research topic in the field of Information Systems and Management Science [4, 5]. Many researchers have devoted a lot in the acceptance of Information Technology and Mobile SNS [6-10]. In these studies, theory of reasoned action (TRA) and technology acceptance model (TAM) are often employed to predict and illuminate the acceptance of information system or information technology. Because these studies are usually focused on the relationship of different influence factors of acceptance, there continues to be a gap in understanding the differences between male and female to engage in Mobile SNS.

Hence, this research aims to investigate the moderating effects of gender in the acceptance of Mobile SNS and empirically disclose the gender differences. This empirical study will be useful to test acceptance theories, provide a more comprehensive understanding of mobile SNS for different gender, and help service providers to attract more users in a targeted manner.

\section{Literature Review and Theoretical Background}

Because little research has been conducted to examine the gender differences in the acceptance of Mobile SNS, this paper reviews the literature in four main areas: 
technology acceptance and UTAUT theory, SNS acceptance, moderating effects of gender, perceived enjoyment

\subsection{Technology Acceptance and UTAUT Theory}

Technology acceptance has been thoroughly researched in the field of information systems. Many theories have been developed to explain and predict user's intention to use a specific information technology.

In this field, Theory of Reasoned Action (TRA) and Technology Acceptance Model (TAM) are often used to explain user's behavior.

TRA can predict user's actions in the field of information system and marketing, which proves user's attitude and subjective norm influence user's behavior intention.

Based on TRA, TAM proposed by Davis is often used by lots of researchers in the field of information system adoption (Figure 1). In TAM, perceived usefulness (PU) and perceived ease of use (PEU) are proved to be able to explain user's behavior intention. TAM is successfully to explain the acceptance behavior of information technologies, such as mobile payment, online games, facebook, etc [8, 10-12], and exhibit sufficient robustness.

Because the description of external variables in TAM isn't clear enough, moderating variables are not considered, and TAM is much more suitable for stand-alone system, some researchers wish to improve TAM.

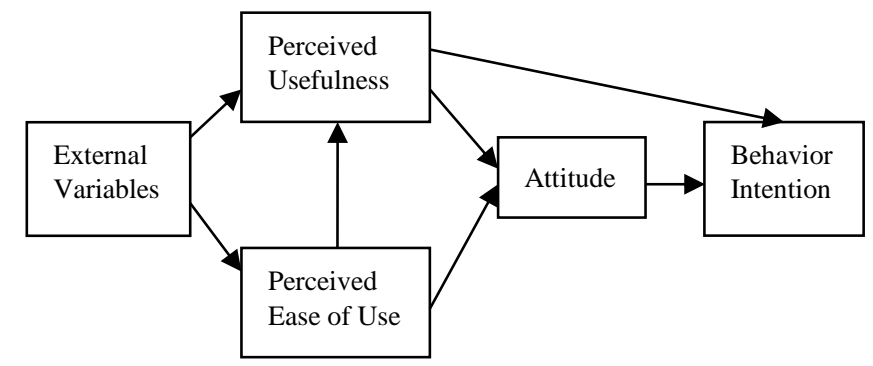

Figure 1. Technology Acceptance Model (TAM)

In the year of 2003, based on TAM and other theories, Venkatesh et al proposed Unified Theory of Acceptance and Use of Technology (UTNUT) model, which shows in Figure 2 [9].

In UTAUT, Performance Expectancy (PE) is defined as the degree to which an individual believes that using the system will help him or her to attain gains in job performance, which is similar with the Perceived Usefulness in TAM. In fact, PE comes from 5 models: TAM, MM, MPCU, IDT and SCT. In these models, PE is the strongest predictor of behavioral intention.

Effort Expectancy (EE) is defined as the degree of ease associated with the use of the system, which is similar with the Perceived Ease of Use in TAM.

Social Influence (SI) is defined as the degree to which an individual perceives that important others believe he or she should use the system.

Facilitating Conditions (FC) is defined as the degree to which an individual believes that an organizational and technical infrastructure exists to support use of the system.

Behavioral Intention (BI) is the willingness of the individual to a certain behavior.

According to UTAUT, PE, EE and SI positively affect BI, BI and FC positively affect user's Use Behavior (UB).

In UTAUT, there are four moderators: gender, age, experience and voluntariness of use. According to the model, the influence of PE on BI, EE on BI, and SI on BI is moderated by gender. 
Many studies apply UTAUT to explain user's acceptance behavior [13-15]. UTAUT was confirmed to explain $70 \%$ of the variance in behavioral intention, which is better than TAM model. So this paper uses UTAUT to be the basis model.

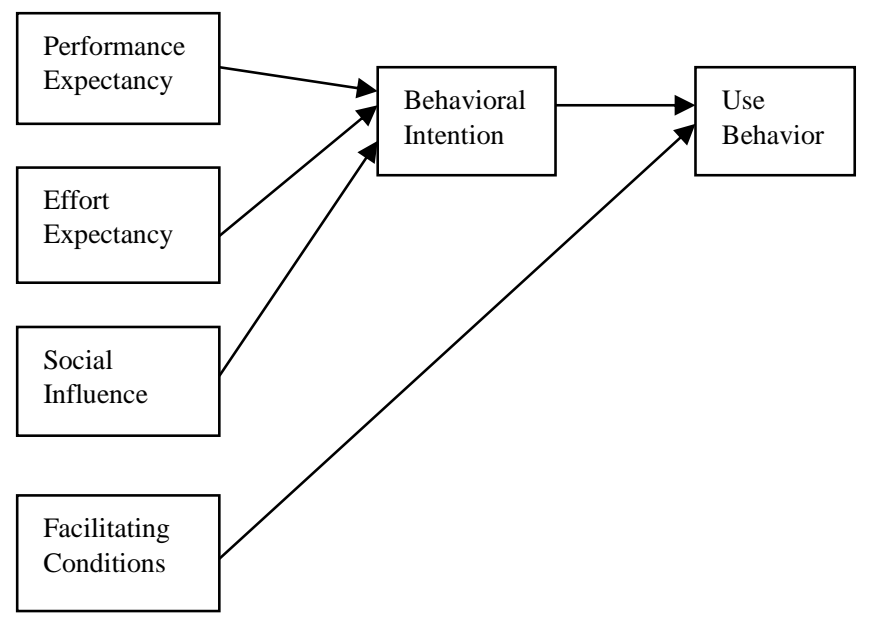

Figure 2. UTAUT Model (Moderator Omitted)

\subsection{SNS Acceptance}

With the proliferation of SNS, understanding SNS acceptance has become a hot topic. Traditional technology acceptance theories also can play an important role in the research topic.

Choi and Hyewon used TAM to predict SNS acceptance and usage [16]. They incorporated Subjective Norm and Perceived Social Capital into TAM to get a better predictive power.

Norazah Mohd and Kee also used TAM to explain Facebook acceptance [10]. They incorporated Perceived Enjoyment into TAM because they believe Perceive Enjoyment affects Perceived Usefulness in hedonic systems.

Leng, Lada, etc. used TAM and TPB (Theory of Planned Behavior) to explore SNS adoption [17]. In addition, they also explore the effect of Intrinsic Motivation.

In fact, there are lots of research results from other researchers [18-21]. From theses research, it can be concluded that only a single theory is used to explain SNS acceptance is not enough, most research incorporate some constructs into some a acceptance theory or incorporate some acceptance theories to get a better explanatory power.

Based above considerations, this paper incorporates some constructs into UTAUT theory.

\subsection{Moderating Effects of Gender}

According to the UTAUT theory, gender has important moderating effects in the acceptance of information technology. In the field of information system research, gender differences are important research direction.

Zhang, Cheung, et al found that in online shopping decision, female are more likely to be influenced by others inconsistent reviews [22].

Park and Nam found that men and women have different levels of digital literacy [23]. Similar results were also confirmed by the research of Lee and Huang [24].

It can be concluded that in the use of information system, men and women have differences. To find these differences can help information system to improve service. 


\subsection{Perceived Enjoyment}

In the year of 2004, Dohlakia et al pointed out that people can be aware of entertainment value from online virtual community [25]. Entertainment value is derived from fun and relaxation through playing or interacting with others. People have the willingness to achieve entertainment value, so Perceived Enjoyment (PEM) has important influence for people to use some a system.

Perceived Enjoyment is defined as the extent to which fun or entertainment value can be derived from using the system. In [4], PEM is used to explain the acceptance of Web Site. In other studies, PEM is incorporated into TAM to explain the acceptance behavior of WWW or M-Commerce, which contributes a more accurate prediction of user acceptance $[4,26]$. In these studies, PEM has directly influence on BI or Attitude, so this paper believes PEM also affects BI in the acceptance of Mobile SNS.

Based on the above considerations, this paper incorporates PEM into UTAUT to explain user acceptance of Mobile SNS.

\section{Research Hypotheses and Model}

\subsection{Gender, PE and BI}

UTAUT points out that the influence of PE on BI is moderated by gender. The effect of $\mathrm{PE}$ on BI has been found to be stronger for male than female in the acceptance of information system [9]. This paper believes the moderating effect also exist in the acceptance of Mobile SNS. So the following hypotheses can be obtained.

Hypothesis 1.1: PE positively affects BI toward Mobile SNS.

Hypothesis 1.2: Gender moderates the influence of PE on BI toward Mobile SNS.

\subsection{Gender, EE and BI}

UTAUT points out that the influence of EE on BI is moderated by gender. The effect of EE on BI has been found to be stronger for female than male in the acceptance of information system [9]. This paper believes the moderating effect also exist in the acceptance of Mobile SNS. So the following hypotheses can be obtained.

Hypothesis 2.1: EE positively affects BI toward Mobile SNS.

Hypothesis 2.2: Gender moderates the influence of EE on BI toward Mobile SNS.

\subsection{Gender, SI and BI}

UTAUT points out that the influence of SI on BI is moderated by gender. The effect of SI on BI has been found to be stronger for female than male in the acceptance of information system [9]. This paper believes the moderating effect also exist in the acceptance of Mobile SNS. So the following hypotheses can be obtained.

Hypothesis 3.1: SI positively affects BI toward Mobile SNS.

Hypothesis 3.2: Gender moderates the influence of SI on BI toward Mobile SNS.

\subsection{Gender, FC and UB}

UTAUT doesn't point out there exists gender's moderating effect between FC and UB. This paper believes there is difference in the cognition of FC between men and women, and wishes to make an exploratory analysis to find whether the difference really exists. So the following hypotheses can be obtained.

Hypothesis 4.1: FC positively affects UB toward Mobile SNS. 
Hypothesis 4.2: Gender moderates the influence of FC on UB toward Mobile SNS.

\subsection{Gender, PEM and BI}

Many studies point out PEM has influence on BI or user's Attitude. A few focuses on how gender can moderate the influence [27]. This paper believes there is difference in the cognition of PEM between men and women, and also wishes to make an exploratory analysis to find whether the difference really exists. So the following hypotheses can be obtained.

Hypothesis 5.1: PEM positively affects BI toward Mobile SNS.

Hypothesis 5.2: Gender moderates the influence of PEM on BI toward Mobile SNS.

\subsection{Gender, BI and UB}

UTAUT doesn't point out there exists gender's moderating effect between BI and UB. This paper believes there is difference in the cognition of BI between men and women, and wishes to make an exploratory analysis to find whether the difference really exists. So the following hypotheses can be obtained.

Hypothesis 6.1: BI positively affects UB toward Mobile SNS.

Hypothesis 6.2: Gender moderates the influence of BI on UB toward Mobile SNS.

\subsection{Research Model}

Based on the above considerations, the research model can be obtained (Figure 3).

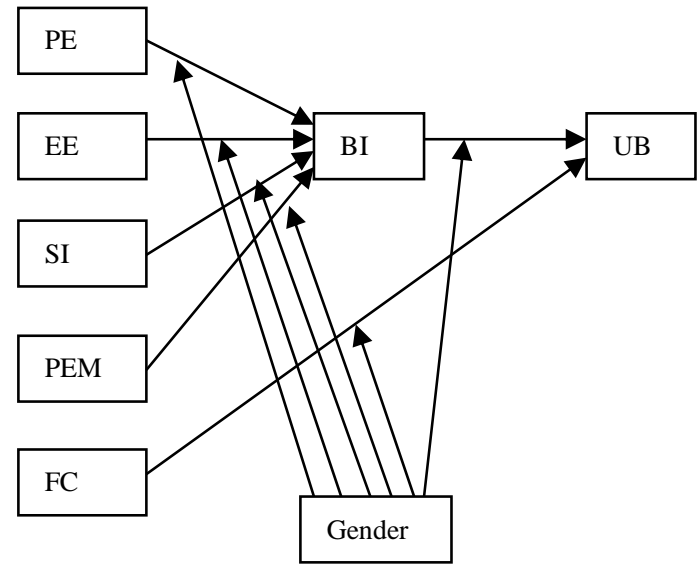

Figure 3. Research Model

\section{Research Methodology}

\subsection{Research Design}

The paper uses questionnaire survey empirical research method to verify the research model shown in Figure 3. The measures used to operationalize the constructs are taken from relevant prior classical studies to ensure the reliability and validity. Some existing measures are adapted according to the context of this study. Table I shows the relevant prior research which used as the basis for constructs operationalization in this paper. 
Table 1. Relevant References for Model Constructs

\begin{tabular}{|l|l|}
\hline \multicolumn{1}{|c|}{ Construct } & \multicolumn{1}{c|}{ Sources } \\
\hline PE & Adapted from [8], [9], [28] \\
\hline EE & Adapted from [9] \\
\hline SI & Adapted from [9], [29], [30] \\
\hline PEM & Adapted from [5] \\
\hline FC & Adapted from [9] \\
\hline BI & Adapted from [8], [9], [29] \\
\hline UB & Adapted from [31], [32] \\
\hline
\end{tabular}

The questionnaire uses 5-point Likert scale method to explore the study, ranging from 1 (strongly disagree) to 5 (strongly agree).

\subsection{Survey and Data Collection}

In order to pretest rationality of the questionnaire, 20 cases are investigated before the formal survey. According to the result of pretest, a few measures which maybe confuse the respondents are modified.

After the pretest, the formal survey is carried out. People in China who would maybe use Mobile SNS are chosen as target population. The relevant demographic and other characteristics of the respondents are presented in Table II.

Table 2. Characteristics of the Respondents

\begin{tabular}{|c|c|c|}
\hline Characteristic & Number & Percentage \\
\hline \multicolumn{3}{|l|}{ Gender } \\
\hline Male & 160 & $44.57 \%$ \\
\hline Female & 199 & $55.43 \%$ \\
\hline \multicolumn{3}{|l|}{ Age } \\
\hline$<20$ & 106 & $29.53 \%$ \\
\hline $20-30$ & 247 & $68.80 \%$ \\
\hline$>30$ & 6 & $1.67 \%$ \\
\hline \multicolumn{3}{|l|}{ Education } \\
\hline Senior high school or below & 12 & $3.34 \%$ \\
\hline Junior college or above & 347 & $96.66 \%$ \\
\hline
\end{tabular}

\section{Data Analysis and Results}

\subsection{Reliability Analysis}

Cronbach's $\alpha$ is used to evaluate reliability. Cronbach's $\alpha$ of 7 constructs are all above 0.7 , which indicates the survey has adequate reliability (Table III). 
Table 3. Indicators of Reliability

\begin{tabular}{|c|c|c|c|}
\hline Construct & items & $\begin{array}{l}\text { Cronbach's } \alpha \\
\text { (item deleted) }\end{array}$ & $\begin{array}{c}\text { Cronbach's } \\
\alpha\end{array}$ \\
\hline \multirow{4}{*}{$\mathrm{PE}$} & pe1 & 0.879 & \multirow{4}{*}{0.897} \\
\hline & pe2 & 0.851 & \\
\hline & pe3 & 0.864 & \\
\hline & pe4 & 0.872 & \\
\hline \multirow{4}{*}{$\mathrm{EE}$} & ee1 & 0.674 & \multirow{4}{*}{0.728} \\
\hline & ee2 & 0.642 & \\
\hline & ee3 & 0.675 & \\
\hline & ee4 & 0.679 & \\
\hline \multirow{4}{*}{ SI } & si1 & 0.744 & \multirow{4}{*}{0.809} \\
\hline & si2 & 0.752 & \\
\hline & si3 & 0.739 & \\
\hline & si4 & 0.806 & \\
\hline \multirow{4}{*}{ PEM } & pem1 & 0.807 & \multirow{4}{*}{0.859} \\
\hline & pem2 & 0.805 & \\
\hline & pem3 & 0.834 & \\
\hline & pem4 & 0.833 & \\
\hline \multirow{3}{*}{ FC } & $\mathrm{fc} 1$ & 0.787 & \multirow{3}{*}{0.861} \\
\hline & $\mathrm{fc} 2$ & 0.784 & \\
\hline & $\mathrm{fc} 3$ & 0.843 & \\
\hline \multirow{3}{*}{ BI } & bi1 & 0.755 & \multirow{3}{*}{0.822} \\
\hline & bi2 & 0.794 & \\
\hline & bi3 & 0.714 & \\
\hline \multirow{2}{*}{ UB } & ub1 & NULL & \multirow{2}{*}{0.771} \\
\hline & ub2 & NULL & \\
\hline
\end{tabular}

\subsection{Validity Analysis}

The measures of this study mostly refer to the relevant classical research, so the model has good content validity. An exploratory factor analysis is conducted to verify construct validity, in which factor loadings and KMO value are focused. Factor loadings of each item are all above 0.5 and KMO value of each viriable are all above 0.7(except UB), which shows the model has good construct validity (Table IV). 
Table 4. Indicators of Validity

\begin{tabular}{|c|c|c|c|c|}
\hline Construct & Items & $\begin{array}{l}\text { Factor } \\
\text { Loading }\end{array}$ & KMO & $\mathbf{P}$ \\
\hline \multirow{4}{*}{ PE } & pe1 & 0.793 & \multirow{4}{*}{0.840} & \multirow{4}{*}{0.000} \\
\hline & pe2 & 0.880 & & \\
\hline & pe3 & 0.831 & & \\
\hline & pe4 & 0.809 & & \\
\hline \multirow{4}{*}{$\mathrm{EE}$} & ee 1 & 0.626 & \multirow{4}{*}{0.713} & \multirow{4}{*}{0.000} \\
\hline & ee2 & 0.724 & & \\
\hline & ee3 & 0.575 & & \\
\hline & ee4 & 0.608 & & \\
\hline \multirow{4}{*}{ SI } & si1 & 0.752 & \multirow{4}{*}{0.797} & \multirow{4}{*}{0.000} \\
\hline & si2 & 0.759 & & \\
\hline & si3 & 0.762 & & \\
\hline & si4 & 0.615 & & \\
\hline \multirow{4}{*}{ PEM } & pem1 & 0.802 & \multirow{4}{*}{0.819} & \multirow{4}{*}{0.000} \\
\hline & pem2 & 0.809 & & \\
\hline & pem3 & 0.757 & & \\
\hline & pem4 & 0.750 & & \\
\hline \multirow{3}{*}{ FC } & $\mathrm{fc} 1$ & 0.834 & \multirow{3}{*}{0.728} & \multirow{3}{*}{0.000} \\
\hline & $\mathrm{fc} 2$ & 0.863 & & \\
\hline & $\mathrm{fc} 3$ & 0.770 & & \\
\hline \multirow{3}{*}{ BI } & bi1 & 0.809 & \multirow{3}{*}{0.710} & \multirow{3}{*}{0.000} \\
\hline & bi 2 & 0.720 & & \\
\hline & bi3 & 0.786 & & \\
\hline UB & ub1 & 0.841 & 0.500 & 0.000 \\
\hline
\end{tabular}

\subsection{Confirmatory Factor Analysis}

An internal consistency analysis is conducted. The CR (composite reliability) and AVE (average variance extracted amount) are used for the test. CR of each construct are all above 0.7 and AVE of each construct are all above or close to 0.5, which shows the good internal consistency, which shows in Table V.

Table 5. Internal Consistency

\begin{tabular}{|l|l|l|l|l|}
\hline Construct & Items & $\begin{array}{c}\text { Factor } \\
\text { Loading }\end{array}$ & CR & AVE \\
\hline \multirow{2}{*}{ PE } & pe1 & 0.793 & \multirow{2}{*}{0.898} & 0.687 \\
\cline { 2 - 5 } & pe2 & 0.880 & & \\
\hline
\end{tabular}




\begin{tabular}{|c|c|c|c|c|}
\hline Construct & Items & $\begin{array}{c}\text { Factor } \\
\text { Loading }\end{array}$ & CR & AVE \\
\hline & pe3 & 0.831 & & \\
\hline & pe 4 & 0.809 & & \\
\hline \multirow{4}{*}{ EE } & ee1 & 0.626 & \multirow{4}{*}{0.729} & \multirow{4}{*}{0.404} \\
\hline & ee2 & 0.724 & & \\
\hline & ee3 & 0.575 & & \\
\hline & ee4 & 0.608 & & \\
\hline \multirow{4}{*}{ SI } & si 1 & 0.752 & \multirow{4}{*}{0.815} & \multirow{4}{*}{0.525} \\
\hline & si 2 & 0.759 & & \\
\hline & si3 & 0.762 & & \\
\hline & si4 & 0.615 & & \\
\hline \multirow{4}{*}{ PEM } & pem1 & 0.802 & \multirow{4}{*}{0.861} & \multirow{4}{*}{0.608} \\
\hline & pem2 & 0.809 & & \\
\hline & pem3 & 0.757 & & \\
\hline & pem4 & 0.750 & & \\
\hline \multirow{3}{*}{ FC } & fc1 & 0.834 & \multirow{3}{*}{0.863} & \multirow{3}{*}{0.678} \\
\hline & fc2 & 0.863 & & \\
\hline & $\mathrm{fc} 3$ & 0.770 & & \\
\hline \multirow{3}{*}{ BI } & bi1 & 0.809 & \multirow{3}{*}{0.816} & \multirow{3}{*}{0.597} \\
\hline & bi 2 & 0.720 & & \\
\hline & bi3 & 0.786 & & \\
\hline UB & ub1 & 0.841 & 0.785 & 0.646 \\
\hline
\end{tabular}

Table 6. Model Fit Indicators

\begin{tabular}{|l|l|l|}
\hline \multicolumn{1}{|c|}{ Indicator } & \multicolumn{1}{c|}{ Value } & \multicolumn{1}{c|}{ Acceptable Value } \\
\hline CMIN/DF & 2.304 & $1 \leq \mathrm{CMIN} / \mathrm{DF} \leq 3$ \\
\hline GFI & 0.826 & $\geq 0.8$ \\
\hline AGFI & 0.788 & $\geq 0.8$ \\
\hline NFI & 0.809 & $\geq 0.8$ \\
\hline CFI & 0.881 & $\geq 0.8$ \\
\hline RMSR & 0.043 & $\leq 0.05$ \\
\hline
\end{tabular}

Then, a confirmatory factor analysis using AMOS is conducted to test the measurement. Comparison of all fit indices with their corresponding acceptable values provides evidence of a good model fit, which shows in Table VI, except that AGFI value is slightly below the acceptable value 0.8 . 
So, it can be concluded that data and the model (Figure 3) match well.

With the AMOS, the standard path coefficient of the research model for male and female users can be obtain, which shows in Figure 4.

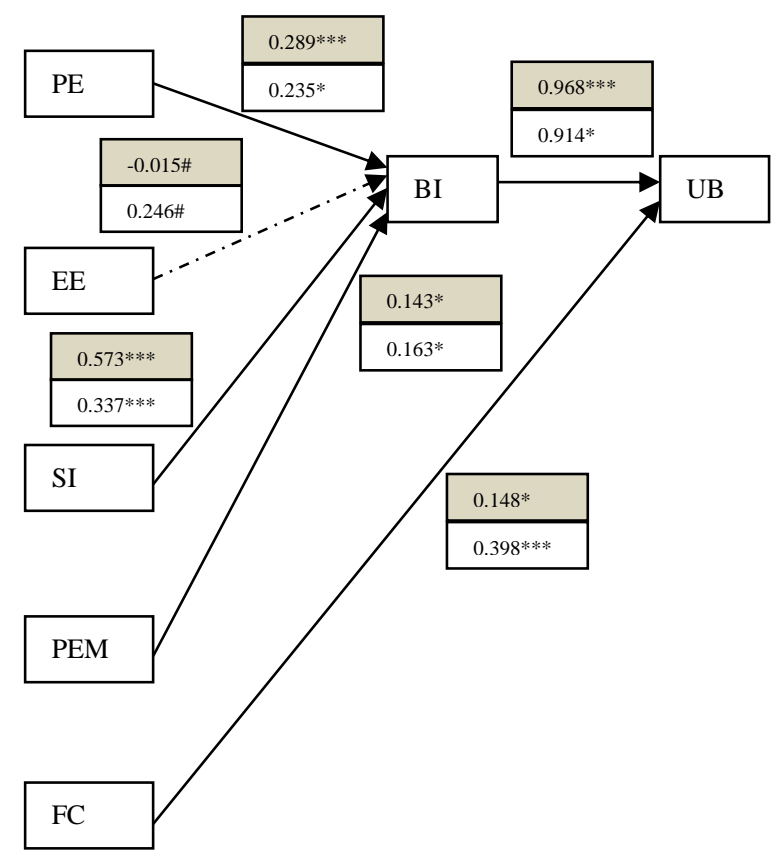

$* p<0.05, * * p<0.01, * * * p<0.001$, \#not significant

Coefficients for male are in the shaded boxes.

\section{Figure 4. Standard Path Coefficients for Male and Female}

According to Figure 4, because of $p>0.05$ both for male and female, Hypothesis 2.1 and Hypothesis 2.2 can't be supported, but Hypothesis 1.1, 3.1, 4.1, 5.1 and 6.1 are supported.

Table 7. Two-group Comparision of Paths

\begin{tabular}{|r|l|l|}
\hline & CMIN & $\Delta$ CMIN from Base Model \\
\hline Unconstrained model & 1430.688 & \\
\hline Constrained paths: & & \\
$\mathrm{PE} \rightarrow \mathrm{BI}$ & 1430.872 & $0.184 \#$ \\
$\mathrm{SI} \rightarrow \mathrm{BI}$ & 1434.619 & $3.931 *$ \\
$\mathrm{PEM} \rightarrow \mathrm{BI}$ & 1430.736 & $0.048 \#$ \\
$\mathrm{FC} \rightarrow \mathrm{UB}$ & 1435.908 & $5.220^{*}$ \\
$\mathrm{BI} \rightarrow \mathrm{UB}$ & 1430.748 & $0.096 \#$ \\
\hline \multicolumn{2}{|c|}{$(p<0.05, * * p<0.01, * * * p<0.001$, \#not significant }
\end{tabular}




\subsection{Moderating Effects of Gender}

A two-group test for examining the gender differences in strength of the path coefficients is conducted. In this analysis, one path coefficient is constrained to be equal across the two gender groups, and the resulting model fit is compared with the base research model, in which all path coefficients are freely estimated using $\triangle \mathrm{CMIN}$.

The results of gender difference analysis are shown in Table VII.

According to Table VII, it can be concluded that Hypothesis 3.2 and Hypothesis 4.2 are supported. So Gender moderates the influence of SI on BI and the influence of FC on UB in the acceptance of Mobile SNS.

\section{Discussions and Implications}

This paper mainly focuses on the moderating effects of gender in the acceptance of Mobile SNS. Data analysis shows that there really exist differences between male and female. In addition, there is a windfall that user's Effort Expectancy (EE) is not associated with Mobile SNS Behavioral Intention both for men and women.

Hypothesis 1.1 (PE positively affects BI toward Mobile SNS) and 3.1 (SI positively affects BI toward Mobile SNS) are supported by the data. These hypotheses come from UTAUT theory and the result is consistent with the UTAUT model, which shows that Performance Expectancy (PE) and Social Influence (SI) are important predictors of user's Mobile SNS acceptance intention both for male and female. This paper confirms the significant roles of Performance Expectancy and Social Influence from UTAUT in the Mobile SNS environments.

Hypothesis 4.1 (FC positively affects UB toward Mobile SNS) and 6.1 (BI positively affects UB toward Mobile SNS) are supported by the data. These hypotheses also come from UTAUT theory and the result is consistent with the UTAUT model too, which shows that Facilitating Conditions (FC) and Behavioral Intention (BI) affect user's acceptance behavior both for male and female. The result further proves that UTATU theory has explanatory power in Mobile SNS environments.

Hypothesis 5.1 (PEM positively affects BI toward Mobile SNS) is supported by the data, which is consistent with relevant studies. In fact, in addition to the existing research, motivation theory also gives some explanation about perceived enjoyment [33]. Motivation theory believes there are two kinds of motivation: intrinsic and extrinsic motivation. Intrinsic motivation refers to the perceived pleasure from engaging in an action, which is similar with Perceived Enjoyment (PEM) in this paper. So, this paper also proves the usefulness of motivation theory in the environments of Mobile SNS.

However, Hypothesis 2.1 (Effort Expectancy positively affects BI towards Mobile SNS.) is not supported by the data, which does not comply with the UTAUT theory both for male and female. This is an unexpected finding of this paper. In a number of information technology acceptance studies, Effort Expectancy (EE) or Perceived Ease of Use (PEU) plays an important role in the user's adoption behavior. In the past, when people try to use some information system to improve their performance, they have to learn how to operate a machine or sophisticated software. In this kind of case, EE or PEU undoubtedly have significant influence on user's acceptance intention. But, in the environment of Mobile SNS, things seem changed. Maybe with the popularity of smart phones, iOS and Android smart phone operating system provide users a great convenience, and users would feel little difficult to learn and use smart phones and mobile applications. Even for the elderly and children, they do not feel any difficulty in using a smart phone. So, it can be concluded that service providers have been doing a good job to enable users to easily use Mobile SNS. This result cannot prove UTAUT theory is wrong, but it shows the limitation of UTAUT in the environments of Mobile SNS. But after amendment, UTAUT theory still has a strong explanatory power. 
Because Hypothesis 2.1 is not supported, Hypothesis 2.2 (Gender moderates the influence of EE on BI toward Mobile SNS) seems meaningless. In UTATU theory, the effect of EE on BI is stronger for women, but in Mobile SNS, the effect is not significant, so the difference of male and female cannot be clear.

Hypothesis 1.2 (Gender moderates the influence of PE on BI toward Mobile SNS) is not supported, which also does not comply with the UTAUT model. In UTATU, the effect of Performance Expectancy on Behavioral Intention is stronger for men in the environment of traditional information system. Mobile SNS is different with the traditional information system in some organizations. Users often use Mobile SNS in their fragments of time, so for many users, both men and women, to pass the time may be their important aim instead of improve job performance. That's maybe why the moderating effects of gender can't be seen.

Hypothesis 5.2 (Gender moderates the influence of PEM on BI toward Mobile SNS) is not supported. It suggests both male and female users have the same cognition on enjoyment, so the service providers' providing enjoyment or entertainment can both attract men and women to use Mobile SNS. It also implicates that male and female's intrinsic motivation is consistent.

Hypothesis 6.2 (Gender moderates the influence of BI on UB toward Mobile SNS) is not supported. In UTAUT theory, there is no gender moderating effect of Behavioral Intention on Use Behavior, so the result is consistent with UTAUT. It suggests that there is no difference in the conversion from psychological intentions to actual behavior for male and female.

Hypothesis 3.2 (Gender moderates the influence of SI on BI toward Mobile SNS) is supported, which is consistent with the UTAUT model. But it does not comply with [9], which points out that the effect of SI on BI has been found to be stronger for female than male in the acceptance of information system. In this paper, male has a stronger effect. A possible explanation is that, in the Mobile SNS, the number of male users is larger than the number of female users. Another possible explanation is that, maybe men like adventure in a large environment while women like to enjoy the small circle, and the larger friend circle has bigger influence. Of course, these explanations are based solely on speculation, which need further verification. For the service providers, large-scale user interaction of information services would attract much more male users.

Hypothesis 4.2 (Gender moderates the influence of FC on UB toward Mobile SNS) is supported. In UTAUT theory, there is no gender moderating effect of Facilitating Conditions on Use Behavior. In this paper, the effect of FC on UB has been found to be stronger for female than male. A possible explanation is that male has greater passion and desire to obtain and understand information technology. So male has a better Facilitating Conditions than female, thus the influence of FC for male is smaller than female. The reason of this phenomenon still needs further study.

\section{Conclusions, Limitations and Future Studies}

This study conducted an empirical investigation of the gender differences in the acceptance of Mobile SNS. The findings of this paper provide several interesting implications for mobile SNS research and practice. This study proves that UTAUT and Perceived Enjoyment are valid to explain the acceptance of Mobile SNS, especially proves that there are moderating effects of gender.

Despite the useful findings of this study, there are still some limitations.

Firstly, the sample of the study comes from China, so the findings may not be adequate for other countries. Although China has the largest number of Mobile SNS users and therefore likely to be a good country to conduct Mobile SNS acceptance research, it should be remembered that culture and religion also play important role which can influence user's intention. So it should be careful to apply the result to other countries. 
Secondly, as mentioned before, male has stronger influence of SI on BI towards Mobile SNS than female, which is not consistent with [9], which needs further research for the better explanation.

Thirdly, this paper proves female has stronger influence of FC on UB towards Mobile SNS than male, which also needs further research.

Fourthly, according to UTAUT model, age, experience and voluntariness of use are also important moderators. This paper does not examine these moderators, which can be tested in the future work.

\section{Acknowledgements}

The research work is supported by National Natural Science Foundation of China under Grant No. 71261008. The author also acknowledges the help from Yuhui PENG for the data collection.

\section{References}

[1] CNNIC, The 33rd Statistical Report on Internet Development in China, (2014).

[2] CNNIC, the research report of china Internet SNS site, (2012).

[3] O. Kharif, "Social Networking Goes Mobile", BusinessWeek, vol. 5, (2006).

[4] H. Van der Heijden, "Factors influencing the usage of websites: the case of a generic portal in the Netherlands", Information \& Management, vol. 6, no. 40, (2003).

[5] H. Van der Heijden, "User acceptance of hedonic information systems", MIS Quarterly, vol. 4, no. $28,(\mathbf{2 0 0 4})$.

[6] G. C. Bruner II and A. Kumar, "Explaining consumer acceptance of handheld Interrnet devices", Journal of Business Research, vol. 5, no. 58, (2005).

[7] Y. GUO, "User Acceptance of MOSNS Based on TAM Model", Proceedings of Seventh International Conference on Management of e-Commerce and e-Government, (2013); Kunming, China.

[8] F. D. Davis, "Perceived usefulness, perceived ease of use and user acceptance of information technology", MIS Quarterly, vol. 3, no. 13, (1989).

[9] V. Venkatesh, M. G. Morris, G. B. Davis and F. D. Davis, "User Acceptance of Information Technology: Toward a Unified View”, MIS Quarterly, vol. 3, no. 27, (2003).

[10] S. T. R. Norazah, L. Mohd and K. Ker, "Empirical investigation on factors influencing the behavioral intention to use Facebook", Universal Access in the Information Society, vol. 2, no. 11, (2012).

[11] H. F. Lin, "An empirical investigation of mobile banking adoption: The effect of innovation attributes and knowledge-based trust", International Journal of Information Management, vol. 3, no. $31,(\mathbf{2 0 1 1})$.

[12] I. Ha, Y. Yoon and M. Choi, "Determinants of adoption of mobile games under mobile broadband wireless access environment", Information \& Management, vol. 3, no. 44, (2007).

[13] M. S. Samudra and M. Phadtare, "Factors Influencing the Adoption of Mobile Banking with Special Reference to Pune City", ASCI Journal of Management, vol. 1, no. 42, (2012).

[14] V. Venkatesh, J. Y. L. Thong and X. Xu, "Consumer acceptance and Use of Information Technology: Extending the Unified Theory of Acceptance and Use of Technology", MIS Quarterly, vol. 1, no. 36, (2012).

[15] V. Venkatesh, J. Y. L. Thong, F. K. Y. Chan, P. J. H. Hu and S. A. Brown, "Extending the twostage information systems continuance model: incorporating UTAUT predictors and the role of context", Information Systems Journal, vol. 6, no. 21, (2011).

[16] G. Choi and C. Hyewon, "Applying the Technology Acceptance Model to Social Networking Sites (SNS): Impact of Subjective Norm and Social Capital on the Acceptance of SNS", International Journal of Human-Computer Interaction, vol. 10, no. 29, (2013).

[17] G. S. Leng, S. Lada, M. Z. Muhammad, A. A. H. Ag and A. Tamrin, "An Exploration of Social Networking Sites (SNS) Adoption in Malaysia Using Technology Acceptance Model (TAM)", Theory of Planned Behavior (TPB) And Intrinsic Motivation, Journal of Internet Banking \& Commerce, vol. 2, no. 16, (2011).

[18] C. H. Jin, "The perspective of a revised TRAM on social capital building: The case of Facebook usage", Information \& Management, vol. 4, no. 50, (2013).

[19] B. Agata, P. Aneta and R. Patrycja, "Psychological Determinants of Using Facebook: A Research Review”, International Journal of Human-Computer Interaction, vol. 11, no. 29, (2013). 
[20] G. Tobias and K. Irene, "Name-Valence and Physical Attractiveness in Facebook: Their Compensatory Effects on Friendship Acceptance", Journal of Social Psychology, vol. 3, no. 153, (2013).

[21] M. Normah, I. Faridah, W. M. W. Amizah, A. Fauzizh, C. P. Kee and M. M. Haizan, "Diffusion of Innovations: The Adoption of Facebook among Youth in Malaysia", Innovation Journal, vol. 3, no. 16, (2011).

[22] K. Z. K. Zhang, C. M. K. Cheung and M. K. O. Lee, "Examining the moderating effect of inconsistent reviews and its gender differences on consumers' online shopping decision", International Journal of Information Management, vol. 2, no. 34, (2014).

[23] E. Y. Park and S. J. Nam, "An analysis of the digital literacy of people with disabilities in Korea: verification of a moderating effect of gender, education and age", International Journal of Consumer Studies, vol. 4, no. 38, (2014)

[24] C. L. Lee and M. K. Huang, "The Influence of Computer Literacy and Computer Anxiety on Computer Self-Efficacy: The Moderating Effect of Gender. CyberPsychology, Behavior \& Social Networking, vol. 3, no. 17, (2014).

[25] U. M. Dholakia, R. P. Bagozzi and L. K. Pearo, "A social influence model of consumer participation in network- and small-group-based virtual communities", International Journal of Research in Marketing, vol. 3, no. 21, (2004).

[26] J. W. Moon and Y. G. Kim, "Extending the TAM for a world -wide-web context", Information \& Management, vol. 4, no. 38, (2001)

[27] H. Y. Wang and Y. S. Wang, "Gender differences in the perception and acceptance of online games", British Journal of Educational Technology, vol. 5, no. 39, (2008).

[28] H. S. Joon, Y. L. T. James, M. J. Yun and T. K. Yan, "Understanding the behavior o mobile data services consumers", Information Systems Frontiers, vol. 4, no. 10, (2008).

[29] P. Y. K. Chau and P. J. Hu, "Information Technology Acceptance by Individual Professionals: A Model Comparison Approach", Decision Sciences, vol. 4, no. 32, (2001).

[30] S. Taylor and P. A. Todd, "Understanding Information Technology Usage: A Test of Competing Models", Information Systems Research, vol. 2, no. 6, (1995).

[31] A. Yan, "Study on Impacting Factors of Baidu Products Usage Based on UTAUT", Journal of Modern Information, vol. 11, no. 32, (2012).

[32] A. Kankanhalli, B. C. Y. Tan and K. K. Wei, "Contributing Knowledge to Electronic Knowledge Repositories: An Empirical Investigation", MIS Quarterly, vol. 1, no. 29, (2005).

[33] E. Deci, "Effects of externally mediated rewards on intrinsic motivation", Journal of Personality \& Social Psychology, vol. 1, no. 18, (1971). 